TI 2018-051/III

Tinbergen Institute Discussion Paper
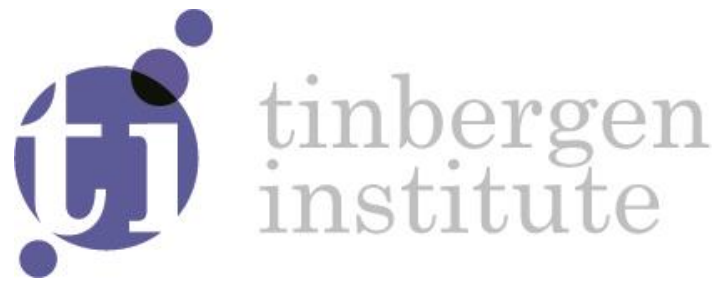

\title{
Why did Warrant Markets Close in China but not Taiwan?
}

\author{
Wing-Keung Wong ${ }^{1}$ \\ Hooi Hoi Lean ${ }^{2}$ \\ Michael McAleer ${ }^{3}$ \\ Feng-Tse Tsai
}

${ }^{1}$ Department of Finance, Fintech Center, and Big Data Research Center, Asia University; Department of Medical Research, China Medical University Hospital, Taiwan; Department of Economics and Finance, Hang Seng Management College, Hong Kong, China; Department of Economics, Lingnan University, Hong Kong, China

2 Economics Program, School of Social Sciences, Universiti Sains Malaysia, Malaysia

${ }^{3}$ Department of Finance, Asia University, Taiwan; Discipline of Business Analytics, University of Sydney Business School, Australia; Econometric Institute, Erasmus School of Economics, Erasmus University Rotterdam, The Netherlands; Department of Economic Analysis and ICAE, Complutense University of Madrid, Spain; Institute of Advanced Sciences, Yokohama National University, Japan

${ }^{4}$ Department of Finance, Asia University, Taiwan 
Tinbergen Institute is the graduate school and research institute in economics of Erasmus University Rotterdam, the University of Amsterdam and VU University Amsterdam.

Contact: discussionpapers@tinbergen.nl

More TI discussion papers can be downloaded at http://www.tinbergen.nl

Tinbergen Institute has two locations:

Tinbergen Institute Amsterdam

Gustav Mahlerplein 117

1082 MS Amsterdam

The Netherlands

Tel.: +31(0)205984580

Tinbergen Institute Rotterdam

Burg. Oudlaan 50

3062 PA Rotterdam

The Netherlands

Tel.: +31(0)10408 8900 


\title{
Why did Warrant Markets Close in China but not Taiwan?*
}

\author{
Wing-Keung Wong \\ Department of Finance, Fintech Center, and Big Data Research Center, Asia University \\ Department of Medical Research, China Medical University Hospital, Taiwan \\ Department of Economics and Finance, Hang Seng Management College, Hong Kong, China \\ Department of Economics, Lingnan University, Hong Kong, China
}

Hooi Hooi Lean

Economics Program, School of Social Sciences, Universiti Sains Malaysia, Malaysia

\author{
Michael McAleer \\ Department of Finance, Asia University, Taiwan \\ Discipline of Business Analytics, University of Sydney Business School, Australia \\ Econometric Institute, Erasmus School of Economics, \\ Erasmus University Rotterdam, The Netherlands \\ Department of Economic Analysis and ICAE, Complutense University of Madrid, Spain \\ Institute of Advanced Sciences, Yokohama National University, Japan
}

Feng-Tse Tsai

Department of Finance, Asia University, Taiwan

May 2018

* The first author is grateful to the Research Grants Council of Hong Kong, Asia University, Hang Seng Management College, Lingnan University, and the Ministry of Science and Technology (MOST), Taiwan, and would also like to thank Robert B. Miller and Howard E. Thompson for their continuous guidance and encouragement. The third author wishes to thank the Australian Research Council and the Ministry of Science and Technology (MOST), Taiwan.

Corresponding author: Feng-Tse Tsai (ttsai@asia.edu.tw) 


\begin{abstract}
The paper bridges a gap in the literature by using moment analysis, CAPM statistics, stochastic dominance (SD) test, and volume analysis to examine investor preferences for warrants between China and Taiwan, and investigating why the market for warrants in China has to close while the market for Taiwan warrants is successful. Using moment analysis, it is shown that that buying China warrants has a higher likelihood of losses than its Taiwan counterpart. Using CAPM analysis, in general, both the Sharpe ratio and Jensen index for warrants from the Taiwan market are more reasonable, while that from the China market is too negative. On the other hand, the Treynor index for China warrants shows that China warrants are highly volatile. This could make investors avoid investing in China warrants which, in turn, could lead to its closure. Using SD analysis, though there is no arbitrage opportunity between the China and Taiwan warrant markets, it is shown that the markets for China and Taiwan warrants are not efficient, and second- and third-order risk averters prefer to invest in China warrants to warrants in Taiwan. This implies that the warrant issuers prefer to issue Taiwan warrants than China warrants. Using volume analysis, the China warrant market is much more active than the Taiwan warrant market. This could imply that there are more speculative activities in China than in Taiwan which, in turn, could lead to China's decision to close its warrant market. The findings in the paper are useful for investors for investment decisions regarding Taiwan and China warrants, for academic analysis for modelling Taiwan and China warrants, and policy makers for policy making related to Taiwan and China warrants. In the future, China may rethink reopening warrant markets and learning from mature-covered warrant markets such as Taiwan how to inhibit excess speculation and educate warrant investors.
\end{abstract}

Keywords: Moment analysis, CAPM statistics, Stochastic dominance, Volume analysis, Arbitrage opportunity, Market efficiency, Warrants, China market, Taiwan market.

JEL Classifications: G14, G15. 


\section{Introduction}

The paper compares investor preferences between the two largest warrant markets in Greater China, namely Mainland China and Taiwan. Both markets are politically, economically and financially competitive, and always seem to be catching the eyes of the world. The comparison period was chosen such that China was experiencing reforms and opening up the securities market, while Taiwan was in the process of party rotation and economic transformation.

Warrants are one of the most commonly traded financial products in financial markets internationally. China has been developing its stock markets very well, to be one of the largest stock markets in the world, while the Taiwan stock market is much smaller, being ranked in the top 20 stock exhcanges, according to various international databases (see, for example, http://www.visualcapitalist.com/20-largest-stock-exchanges-world/). On the other hand, the market for warrants is financially successful in Taiwan, which was initiated in 1997, while the market for warrants in China, which was initiated in 2004, was prevalent in Mainland China, especially in 2006, but closed in 2010. For this reason, among others,, it is interesting to study why the market of warrants in China was prevalent in Mainland China, especially in 2006, but closed in 2010.

Most of the warrants traded in China by the end of 2008 were covered warrants, connected with the flotation of non-tradable shares (the Chinese share reform started in 2005, with two share types, tradable shares and non-tradable shares, before the reform). The unique characteristics of China warrants and irrational investor behavior in the China warrant market are important in the financial literature. Therefore, it is interesting to study investor performance and risk preference in the China warrant market. In the case of warrants in China, the warrants can be calls or puts.

When call options are exercised by investors, non-tradable shares are issued by the Chinese company, leaving the total number of outstanding shares unchanged. Therefore, there is no issue about dilution of earnings when warrants are exercised. In this aspect, warrants in China are similar to covered warrants in Europe and Asia. However, covered warrants in Europe 
and Asia are issued by third parties, such as banks whereas, in China, most warrants are issued by separate companies.

After the stock reforms in 2005, China's equity warrants market became the second largest in the world in terms of trading value, after Germany, surpassing Hong Kong in 2006. The growth in the warrants market in China has been constrained by the gradual expiration of reform-related warrants, excessive speculation, and lack of understanding of the warrants market by its participants. The mechanism for creating special warrants designed as a transition to the development of covered warrants has been under hot debate. A more refined regulatory framework and a stronger institutional investor base are needed, and are prerequisites for a smoothly-functioning warrants market.

In order to foster the long-term development of the warrants market in China, financial experts have argued that issuing covered warrants is crucial, together with proper regulation. Domestic brokerages and exchanges have been lobbying the Chinese government to approve the issuance of covered warrants in a more formal setting. Securities firms argue that allowing brokers to launch covered warrants will significantly boost supply. That is, it is expected that the covered warrants will help in pricing securities more efficiently, thereby increasing the market depth of both the warrant and underlying stock markets. At the same time, it may effectively help curb the current speculative sentiment in China's financial markets.

The split-share structure was a legacy of China's initial share issue privatization (SIP), in which state-owned enterprises (SOEs) went public to issue minority tradable shares to institutional and individual investors. On the other hand, the Chinese government withheld control of these listed SOEs by owning majority non-tradable shares. Although the split-share structure played a positive role in facilitating the SIP, it jeopardized China's continued privatization efforts by restricting the tradability of state-owned shares in the secondary market, and also caused serious corporate governance problems, encouraged speculation in the stock market, and blocked mergers and acquisitions.

In 2005, the Split-Share Structure Reform was initiated to dismantle the dual share structure by converting non-tradable shares into tradable shares. The reform effectively removed the 
legal and technical obstacles of transferring state-owned shares to public investors, opening up the gate to China's secondary privatization which, in contrast to the initial SIP, would further liberalize state-owned shares in full circulation.

However, there have been very few studies, if any, comparing the China and Taiwan warrant markets in which both the main participants of securities markets are individual investors or corporate investors. The Taiwan warrant market was established in 1997, while the China warrant market began in 2004. The background of the developing warrant market in Taiwan is to provide diversified investment and hedging tools compared with a tool of compensation in the share reforms in China. The China warrant market became the largest warrant market in the world in terms of trading volume in 2006, shortly after its inception. In 2006, the Taiwan warrant market was ranked at number 9 according to the total trading volume provided by the World Federation of Exchanges (WFE).

Although Greater China share a common culture, the background of developing warrant markets are different in China and Taiwan. In the period 2004 to 2008, Taiwan's economy faced a huge problem because of industry transformation, with many entrepreneurs moving their factories to Mainland China. In addition, Taiwan experienced the first party transition and the ruling party was politically against Chinese authority, while Mainland China was devoted to the reform and opened its market at the same time. Therefore, in addition to political competition between Taiwan and Mainland China, the two economies were also facing industrial competition. Economic development will be reflected in the performance of the securities markets. Among other reasons, it will be interesting to compare the warrant markets in China and Taiwan.

In order to compare the China and Taiwan warrant markets, there are several differences that are worth mentioning. First, China developed its warrant market in 2004 mainly for the purpose of the share-split reform, which was intended to allow government-held non-tradable shares to become tradable in the market. In order to make up possible losses of original tradable shareholders, some corporations issued warrants and granted these warrants as compensation. However, the warrants in Taiwan and Hong Kong are issued by third parties, that is, securities corporations, and not by the corporations themselves. Securities corporations issue warrants, sell them to investors, and hedge by buying underlying stocks. 
Second, the Taiwan warrant market was established in 1997, 7 years earlier than the China warrant market.

In addition, they also play roles of market makers to facilitate market liquidity. In China, corporations themselves issue warrants based on their non-tradable stocks as underlying stocks, and neither hedge nor play as market makers. Third, the number of issued warrants in the two markets differs substantially. In China, there were only 55 warrants traded in the market, but the trading volume was once ranked as the largest in the world. In Taiwan, the warrant market experienced rises and falls, and currently there are more than 10 thousand warrants issued every year. Moreover, Taiwan has both vanilla and exotic types of warrant,s while China has only vanilla-type warrants.

Finally, the transaction mechanism in the two markets are different. In Taiwan, trading warrants are similar to trading stocks in terms of trading rules and transaction costs. However, it is distinct from trade stocks and trade warrants in China. The detailed mechanism of the China warrant market is described below.

The China warrant market attracted a lot of funds from investors, and became the largest in the world in terms of total trading volume, even though there were only 55 warrants in the market. The high turnover of warrants in China could be attributed to the warrants " $\mathrm{T}+0$ " trading rule, high volatility, and exmption from transaction taxes. Warrants were the only security in China with a "T+0" trading mechanism, that is, investors are able to sell warrants on the same trading day when they are purchased. On the other hand, stocks could only be sold on the next trading day (that is, the " $\mathrm{T}+1$ ” rule).

Additionally, stock prices are restricted to fluctuate within $10 \%$ of the closing price on the previous trading day, while the range was usually over $25 \%$ of the closing price for the warrant on the preceding trading day. Moreover, trading in warrants was exempted from the $0.2 \%$ to $0.3 \%$ transaction tax or stamp duty, and hence trading warrants benefit from a tax advantage. These special characteristics provided greater flexibility for investors on trading warrants. Therefore, warrants were the only securities for intraday trading, and hence attracted significant trading activities. 
In this paper, we bridge a gap in the literature by using moment analysis, CAPM statistics, SD test, and volume analysis to examine investor preferences for warrants between China and Taiwan, and investigate why the market for warrants in China had to close, while the market in Taiwan is successful financially. Using moment analysis, buying China warrants has a much higher opportunity for making losses as compared with Taiwan. This could make investors avoid investing in China warrants which, in turn, could lead to the closure of the market for warrants.

Using CAPM analysis, we conclude that, in general, both the Sharpe ratio and Jensen index for warrants from the Taiwan market are more attractive financially, while the China market is too negative. On the other hand, the Treynor index for China warrants shows that they are highly volatile. Therefore, China closed its warrant market after the end of the share-split reform, where the warrants expired completely in 2010.

Based on SD analysis, it can be inferred that there are no arbitrage opportunities between the China and Taiwan warrant markets, the markets of China and Taiwan warrants are not efficient, and second- and third-order risk averters prefer to invest in China as compared with Taiwan. This implies that warrant issuers prefer to Taiwan warrants to their counterparts in China. This could be another reason why the market of China warrants closed.

Using volume analysis, the China warrant market is clearly much more active than the Taiwan warrant market. This could imply that there are more speculative activities in China than in Taiwan which, in turn, could lead to China's decision to close its warrant market. The findings in the paper are important for investors for their investment decisions regarding Taiwan and China warrants, challenging to academics for their study on modeling Taiwan and China warrants, and useful for policy makers for their policy making related to Taiwan and China warrants. In the future, China should seriously reconsider reopening its warrant market and learning from mature-covered warrant markets, such as Taiwan, on how to inhibit excess speculation and to educate warrant investors.

The remainder of the paper is organized as follows. Section 2 briefly reviews the literature pertaining to covered warrants and the stochastic dominance rules, as well as the rationale behind the SD tests. The data, sample characteristics, and methodology are discussed in Section 3. The empirical results are analysed in Section 4, while Section 5 gives some concluding remarks. 


\section{Literature Review}

Many studies have investigated Chinese and Taiwanese warrant markets. For example, Xiong and $\mathrm{Yu}$ (2011) find that the daily trading volume of many warrants is more than 3 times that of the issuance volume, even though these put warrants were extremely out of the money between 2005 and 2008. The market is useful for examining price bubbles because of obsevable underlying stock prices and the limited life of the warrants to determine the values of the associated contingent claims. Bubbles can be used to test bubble theories such as rational bubbles, agency problems, gambling behaviour, resale option theory, non-common knowledge of rationality, feedback loop theory, among other interesting topics. The authors conclude that short selling restrictions and heterogeneous beliefs drive bubbles.

Some previous studies have focused on issuance, hedging and expiration effects of warrants on stock returns (Draper et al., 2001; Aitken and Segara, 2005; Liao and Chen, 2010; Chung et al., 2014). For example, Chung et al. (2014) examine the impact of covered warrant hedging on underlying stocks on the Taiwan Stock Exchange. They find significant positive abnormal returns and trading volume before the announcement of issuing warrants, especially for large hedging demand warrants. Their findings show that stock return volatility is positively related to the price elasticity of hedging demand.

Additionally, the authors discover a significant negative effect on stock prices after a call warrant has expired in-the-money because of the liquidation of the hedging portfolio. In China, Liao and Chen (2010) find that the expiration of call warrants has a significantly negative price effect during the last four days of the exercise period, whereas the expiration of put warrants exhibits no significant price effects. Overall, the trading activities of call warrants have a more profound effect than their put counterparts around the expiration day.

Previous studies have also compared the prices of warrants and options with the same underlying stocks. For instance, Li and Zhang (2011) and Chan and Pinder (2000) find derivative warrants generally have higher prices than corresponding options, with the price differences reflecting the liquidity premiums of derivative warrants over options in the Hong Kong and Australian markets, respectively. Horst and Veld (2008) compare the price differences between 16 Euronext Amsterdam options and warrants, and find that investors 
may perceive warrants as another type of instrument, and that the warrants are over-priced over the first five trading days.

Bartram and Fehle (2007) examine the degree of the bid-ask spread between warrants and options in Germany, and find that, with overlapped underlying, both warrants and options experienced lower bid-ask spreads due to competition between options and warrants. Petrella (2006) examines the bid-ask spread of covered warrants in Italy, and finds that the reservation spread plays an important role in determining the warrant spreads that are connected with the underlying spreads.

As the China warrant market is relatively young and speculative, investors have largely participated in the market for its special characteristics, namely the speculative behaviour of retail investors in China warrant markets (Xiong and Yu, 2011). Additionally, speculative activities in the warrant market can be contagious and spill over across stock markets (Liu et al., 2014). Tang and Wang (2013) examine warrant return properties, volatility behaviour and pricing errors, and document a stylized fact that call warrants have considerable linkage with their underlying financial assets, but put warrants have almost none.

The combination of the arbitrage pricing theory and the resale-option bubble theory proposed by Scheinkman and Xiong (2003) is adopted to explain this stylized fact. In addition, Liao et al. (2014) examine the incidence of two types of irrational exercise behaviour in the China warrants market, and find that 121.64 million shares of warrants were either exercised with an immediate loss, or failed to be exercised because of warrant holder ignorance and/or negligence of warrant mechanics.

Furthermore, several studies analysed pricing errors of warrants and hedging risks. For example, Chang et al. (2013) find that the market price of warrants are far higher than the prices from Black-Scholes models using historical volatilities. In addition, warrant prices and their underlying stock prices are not monotonic, perfectly correlated, and following option redundancy properties. Cumulative delta hedge profits for most mature warrants are negative, and these negative profits are mainly from volatility risks, trading value of put warrants, and market risk of call warrants.

Powers and Xiao (2014) adopt three standard pricing models and document that put warrant market prices averaged 1.2 yuan more than model-generated prices (over-priced), while call 
warrant prices averaged 1.9 yuan less (under-priced). The authors explain the mispricing due to an implicit discount on the value of stocks when pricing warrants as investors take the potential burst of a stock market bubble into account and a premium on warrants to fulfill speculation purpose or tax advantage.

Liao et al. (2012) observe that creation mechanics (that is, increasing the supply of securities) similar with the short-selling property is useful for reducing bubble issues in China warrant market,s but additional warrant supply can only reduce instead of eliminating bubbles. Fung et al. (2009) review the development of the China warrants market, and highlight the issues of over-speculation and lacking of recognition of participants. The authors suggest that the market requires a more regulated structure and more institutional investors as the cornerstone of the market.

Some studies have applied MV, CAPM, and SD to warrant markets. For example, Chan et al. (2012) examine in the UK covered warrants market by using SD. Their empirical results show that neither covered warrants nor their underlying shares stochastically dominate each other, implying both markets are efficient. They also find that UK covered warrant returns efficiently reflect the return information of the underlying shares from a likelihood ratio (LR) test. As distinct from their analysis on warrants and their underlying shares, we compare warrants in the China and Taiwan markets with similarities (for example, retail investors are main market participants) and differences (for example, the issuers are share-reform companies in China and securities companies in Taiwan) in terms of stochastic dominance.

A variety of interesting papers have applied the MV rule, CAPM statistics, and SD tests to examine the performance of other markets. For example, applying the SD test and other techniques, Abid et al. (2009) investigate the performance of different option strategies; Qiao et al. (2012, 2013) and Lean et al. (2010, 2015) evaluate the relationship between spot and futures prices; Bouri et al. (2018) study the role of wine investment within a portfolio of different assets; Qiao and Wong (2015) and Tsang et al. (2016) examine whether the housing market in Hong Kong is efficient; Hoang et al. (2015a, b, 2018) and Khamlichi et al. (2018) examine the role of gold in the diversification of portfolios; Vieito et al. (2015) and Zhu et al. (2018) investigate whether the financial crisis had any positive impacts on stock markets; Broll et al. (2006, 2015) analyse banks behaviour; Egozcue and Wong (2010), Egozcue et al. (2011), Abid et al. (2014), and Lozza et al. (2018) examine investor behaviour in 
diversification; Fong et al. (2005, 2008) and Lean et al. (2007) study investor behaviour in stock markets; Ma and Wong (2010), Alghalith et al. (2016), Guo et al. (2017), and Niu et al. (2017) examine different risk measures; and Chiang et al. (2008) and Lean et al. (2013) evaluate the performance of different funds.

\section{Data and Methodology}

\subsection{Data}

The warrant data are obtained from the Taiwan Economic Journal (TEJ). There are 55 warrants listed in the Shanghai and Shenzen Stock Exchanges between 2005 and 2009 (65 warrants were issued in the period, but only 55 of them were listed). For comparison, we randomly select 44 covered warrants of which the underlying stocks are in the list of the Taiwan 50 index in the same period (from 2005 to 2009, 44 of the top 50 Taiwan companies were issued corresponding warrants). The daily data include tickers, warrant prices, underlying stock prices, adjusted strike prices, data dates, issuance dates, maturity dates, and others. The conclusions are drawn based on the selected data.

China and Taiuwan warrants are denoted by $\mathrm{C}$ and $\mathrm{T}$, respectively. As there are too many warrants in both the China and Taiwan markets, we follow Wong et al. (2008) in selecting the most representative warrants that have the maximum and minimum values of the of mean, standard deviation, and Sharpe ratio for both China and Taiwan. In addition, we include the maximum and minimum of the beta value, Jensen index, and Treynor index for both China and Taiwan.

The China warrants are denoted as: C06 for the minimum Sharpe ratio; C12 for the maximum Treynor index; C14 for the minimum mean and the minimum Jensen index; C23 for the maximum mean, the maximum Sharpe ratio, and the maximum Jensen index; C44 for the minimum standard deviation; C47 for the maximum standard deviation and the minimum beta value; C52 for the maximum beta value; and C55 for the minimum Treynor index.

The Taiwan warrants are denoted as: T1 for the minimum Jensen index; T12 for the maximum standard deviation; T13 for the minimum mean; T15 for the minimum Sharpe 
ratio; $\mathrm{T} 17$ for the minimum standard deviation, the maximum Sharpe ratio, the minimum beta value, and the maximum Treynor index; T25 for the minimum Treynor index; T26 for the maximum beta value; and T33 for the maximum mean and the maximum Jensen index.

\subsection{Methodology}

In this paper, we use the MV rule, CAPM statistics, SD test, and volume analysis to examine the investor preferences towards the warrants between China and Taiwan. We first discuss the MV rule in the following subsection.

\subsubsection{Mean-variance (MV) criteria}

Define $U_{j}$ as the set of utility functions such that:

$$
U_{j}=\left\{u:(-1)^{i+1} u^{(i)} \geq 0, i=1, \cdots, j\right\}
$$

where $u^{(i)}$ is the $i^{\text {th }}$ derivative of the utility function $U$.

For the returns $\mathrm{Y}$ and $\mathrm{Z}$ of any two assets or portfolios with means $\mu_{\mathrm{y}}$ and $\mu_{\mathrm{z}}$ and standard deviations $\sigma_{\mathrm{y}}$ and $\sigma_{\mathrm{z}}$, respectively, the MV rule (Markowitz 1952; Bai, et al., 2009; Leung, et al., 2012) is such that $\mathrm{Y}$ is said to dominate $\mathrm{Z}$ if $\mu_{\mathrm{y}} \geq \mu_{\mathrm{z}}$ and $\sigma_{\mathrm{y}} \leq \sigma_{\mathrm{z}}$, and if the inequality holds in at least one of the two conditions. Wong (2007) and Guo and Wong (2016) show that if $\mathrm{Y}$ dominates $\mathrm{Z}$ by the MV rule, denoted by $\mathrm{Y}>_{M V} \mathrm{Z}$, then risk averters with $u^{(1)}>0$ and $u^{(2)}$ $<0$ will attain higher expected utility by holding $\mathrm{Y}$ than $\mathrm{Z}$ under certain conditions. The theory can be extended to non-differentiable utilities (see Wong and Ma, 2008).

\subsubsection{Stochastic dominance (SD) approach}

Let $Y$ and $Z$ represent the returns of two assets or portfolios with a common support of $\Omega=[a, b](a<b)$, cumulative distribution functions (CDFs), $F$ and $G$, and corresponding probability density functions (PDFs), $f$ and $g$, respectively, so that we define:

$$
H_{0}=h, \quad H_{j}(x)=\int_{a}^{x} H_{j-1}(t) d t
$$

for $h=f, g$; $H=F, G$; for any integer $j$. 
We call the integral $H_{j}$ the $j^{\text {th }}$-order integral for $H=F, G$. $Y$ is said to dominate $Z$ by FSD (SSD, TSD), denoted by $Y \succ_{1} Z\left(Y \succ_{2} Z, Y \succ_{3} Z\right)$, if $F_{1}(x) \leq G_{1}(x)\left(F_{2}(x) \leq G_{2}(x)\right.$, $F_{3}(x) \leq G_{3}(x)$ ) for all possible returns $x$, and the strict inequality holds for at least one small open interval of $x$, where FSD (SSD, TSD) denotes first-order (second-order, third-order) SD, respectively. For $Y \succ_{3} Z$, we need a further condition: $\mu_{Y} \geq \mu_{Z}$ (see Sriboonchitta et al. (2009), Levy (2015), Guo and Wong (2016), and the references listed therein, for further information on the SD definitions for any order.

The SD tests have been well developed (Davidson and Duclos, DD, 2000; Bai, et al., 2011; Ng, et al., 2017) to allow statistical significance to be determined. The SD test developed by DD is found to be powerful, less conservative in size, and robust to non-iid and heteroscedastic data (Lean et al., 2008). As Bai et al. (2015) derive the limiting process of the DD statistic when the underlying processes are dependent or independent, we use their SD tests in the empirical analysis.

Let $\left\{f_{i}\right\}\left(i=1,2, \cdots n_{f}\right)$ and $\left\{g_{i}\right\}\left(i=1,2, \cdots n_{g}\right)$ be observations drawn from the returns of any two assets or portfolios, $Y$ and $Z$, with CDFs $F$ and $G$, respectively. For a grid of preselected points $x_{1}, x_{2} \ldots x_{k}$, the $j^{\text {th }}$-order SD test statistic, $T_{j}(x)(j=1,2$, and 3$)$, is defined as:

$$
T_{j}(x)=\frac{\hat{F}_{j}(x)-\hat{G}_{j}(x)}{\sqrt{\widehat{V}_{j}(x)}}
$$

where

$$
\begin{aligned}
& \hat{V}_{j}(x)=\hat{V}_{F_{j}}(x)+\hat{V}_{G_{j}}(x)-2 \hat{V}_{F G_{j}}(x) ; \quad \hat{H}_{j}(x)=\frac{1}{N_{h}(j-1) !} \sum_{i=1}^{N_{h}}\left(x-h_{i}\right)_{+}^{j-1}, \\
& \hat{V}_{H_{j}}(x)=\frac{1}{N_{h}}\left[\frac{1}{N_{h}((j-1) !)^{2}} \sum_{i=1}^{N_{h}}\left(x-h_{i}\right)_{+}^{2(j-1)}-\hat{H}_{j}(x)^{2}\right], H=F, G ; h=f, g ; \\
& \hat{V}_{F G_{j}}(x)=\frac{1}{N_{h}}\left[\frac{1}{N_{h}((j-1) !)^{2}} \sum_{i=1}^{N_{h}}\left(x-f_{i}\right)_{+}^{j-1}\left(x-g_{i}\right)_{+}^{j-1}-\hat{F}_{j}(x) \hat{G}_{j}(x)\right],
\end{aligned}
$$

$F_{j}$ and $G_{j}$ are defined in (2). For all $i=1,2, \ldots, k$, we test the following hypotheses: 


$$
\begin{aligned}
& H_{0}: F_{j}\left(x_{i}\right)=G_{j}\left(x_{i}\right), \text { for all } x_{i} ; \\
& H_{A}: F_{j}\left(x_{i}\right) \neq G_{j}\left(x_{i}\right) \text { for some } x_{i} ; \\
& H_{A 1}: F_{j}\left(x_{i}\right) \leq G_{j}\left(x_{i}\right) \text { for all } x_{i}, F_{j}\left(x_{i}\right)<G_{j}\left(x_{i}\right) \text { for some } x_{i} ; \\
& H_{A 2}: F_{j}\left(x_{i}\right) \geq G_{j}\left(x_{i}\right) \text { for all } x_{i}, F_{j}\left(x_{i}\right)>G_{j}\left(x_{i}\right) \text { for some } x_{i} .
\end{aligned}
$$

Not rejecting either $H_{0}$ or $H_{A}$ implies the non-existence of any SD relationship between $X$ and $Y$. If $H_{A 1}\left(H_{A 2}\right)$ of order one is accepted, then $X(Y)$ stochastically dominates $Y(X)$ at first order, denoted by $\mathrm{X}>_{1} \mathrm{Y}\left(\mathrm{Y}>_{1} \mathrm{X}\right)$. If $H_{A 1}\left(H_{A 2}\right)$ is accepted at order two [three], then $X(Y)$ stochastically dominates $Y(X)$ at second order, denoted by $\mathrm{X}>_{2} \mathrm{Y}\left(\mathrm{Y}>_{2} \mathrm{X}\right)$, $\left[\mathrm{X}>_{3} \mathrm{Y}\left(\mathrm{Y}>_{3} \mathrm{X}\right)\right]$. Readers may refer to Bai et al. (2015) for the decision rules and further information on the tests, and Chan et al. (2016) for testing the third-order SD.

Bai et al. (2015) derive the limiting process of the SD statistic $T_{j}(x)$ so that the SD test can be performed by using $\max _{\mathrm{x}}\left|T_{j}(x)\right|$ to account for the dependency of the partitions. We follow their recommendation in the empirical analysis. As Fong et al. (2005), Lean et al. (2008, 2010), among others, recommend a limited number (100) of grids for comparison, we adopt their suggestion. In order to minimize Type II errors and to accommodate the effect of almost SD (Leshno and Levy, 2002; Guo, et al., 2013, 2014, 2016), we follow Gasbarro et al. (2007), Clark et al. (2016), among others, to use a conservative 5\% cut-off point in examining the proportion of test statistics to draw inferences.

\section{Empirical Results}

This section discusses the empirical results. We use moment analysis, CAPM statistics, SD test, and volume analysis to examine investor preferences for warrants between China and Taiwan, and investigate why the market of warrants in China closed while the market of Taiwan warrants is successful. We note that the moment analysis (Chan et al., 2017) includes the mean-variance (MV) rule and the analysis of higher-order moments.

\subsection{Moments analysis}


The MV rule is used to examine the performance between China and Taiwan warrants. In order to do so, we examine the descriptive statistics of daily excess returns in Table 1 and the results of the $\mathrm{t}$ and $\mathrm{F}$ tests in Table 2 for selected China and Taiwan warrants.

\section{[Tables 1 and 2 here]}

We compare warrants with minimum daily excess returns from China and Taiwan, which are represented by C14 and T13, respectively. From Table 1, the mean excess return of T13 is higher than that of $\mathrm{C} 14$, while the standard deviation of the former is smaller. However, the insignificant $\mathrm{t}$ and F statistics in Table 2 conclude there is no MV dominance between T13 and C14 using the MV approach. We also compare warrants with maximum daily excess returns from China and Taiwan, which are represented by C23 and T33, respectively. Although T33 has larger mean excess returns, it also has a higher standard deviation than C23. Therefore, there is no MV dominance between T33 and C23 using the MV approach.

Next we compare warrants with minimum (maximum) daily standard deviations from China and Taiwan, which are represented by C44 and T17 (C47 and T12), respectively. It is found that T17 has significantly higher mean excess return and significantly higher standard deviation than C44, so there is no MV dominance between T33 and C23 using the MV approach. However, T12 has insignificantly higher mean excess return and significantly higher standard deviation than C47, implying that C47 dominates T12 using the MV approach. With the MV criterion, we find that five pairs of China warrants dominate Taiwan warrants, and three pairs of Taiwan warrants dominate China warrants. The other four pairs have not shown any dominance between China and Taiwan warrants.

Tables 1 and 2 indicate the following. First, the mean excess returns are, in general, higher for Taiwan warrants, while most of the mean excess returns for both China and Taiwan warrants are negative, which implies that the mean excess returns of China warrants are more negative. This could make investors avoid investing in China warrants which, in turn, could lead to the closure of the market for China warrants.

In addition, most of the China warrants are significant and negatively skewed, while most of the Taiwan warrants are either significantly and positively skewed or are not significantly skewed. Moreover, China warrants have much greater and significant kurtosis. These 
statistics suggest that buying China warrants has a higher chance of accruing losses. The skewness and kurtosis suggest that the opportunities of returns for China warrants being negative are very high. This could make investors avoid investing in China warrants which, in turn, could lead to the closure of the warrants market in China.

\subsection{CAPM analysis}

For the CAPM statistics, the Sharpe ratio that measures the excess return per unit of risk is the conventional formula for stock evaluation where the risk is determined by the standard deviation. The higher isthe Sharpe ratio, the better is the portfolio return relative to risk, or the larger is the excess return per unit of risk in a portfolio. All Sharpe ratios are negative, except for C23, T17 and T33, while the Sharpe ratio of T17 is higher than all the eight selected warrants in China. Nearly all the Sharpe ratios are negative, which implies that, in general, investors are losing money in both China and Taiwan warrant markets.

The Sharpe ratio of T17 is higher than all the eight selected warrants in China. In general, the Sharpe ratio for warrants for Taiwan is higher than those in China, which indicates that Taiwan warrants perform better than their counterparts in China. It can be concluded that, in general, the Sharpe ratio for warrants for Taiwan is more appealing, while that from China is too negative. This could make investors avoid investing in China warrants which, in turn, could lead to the closure of its market.

Similar to the Sharpe ratio, all Jensen indexes are also negative, except for T17 and T33. T33 has the highest Jensen index among all the warrants. A higher Jensen index suggests a higher level of return given the level of risk (systematic or market) on the investment. A low Jensen index, such as a negative number, indicates an inferior performance given the level of risk. The empirical findings that the values of the Jensen index for most warrants from both China and Taiwan are negative imply a poor performance of both warrant markets during the sample period. It is interesting that T33 is higher than all eight selected warrants in China. Nevertheless, the Jensen index of T1 (the Taiwan warrant with minimum Jensen index) is also larger than its counterpart in China, namely C14. 
In general, the Jensen index for warrants for Taiwan is higher than in China, inferring that Taiwan warrants perform better than China warrants. Thus, we can conclude that, in general, the Jensen index for warrants for Taiwan is more appealing, while that from China is too negative. This could make investors avoid investing in China warrants which, in turn, could lead to the closure of the market in China.

The Treynor ratio expresses the relationship of excess fund return, with the beta lying along the security market line taking account of the systematic risk or market volatility as its measure of risk, instead of the standard deviation, as in the Sharpe ratio. The Treynor index for China ranges from -61 to +20 , indicating that China warrants are very volatile. The higher volatility in the China warrants could make investors avoid investing in China warrants which, in turn, makes it more likely that could lead to the closure of the market.

In summary, , CAPM analysis demonstrates that Taiwan warrants perform better than China warrants in terms of the Sharpe ratio and Jensen index. In addition, the China warrant market is volatile for investors according to the Treynor ratio. Therefore, China closed its warrant market after the end of the share-split reform, which expired completely in 2010. In the future, China might rethink reopening its warrant market and learning from mature-covered warrant markets, such as Taiwan, as to how tit might be possible to inhibit excess speculation and to educate warrant investors.

\subsection{SD analysis}

Table 3 reports the SD results based on the modified DD statistics. From the SD results, most of the China warrants stochastically dominate Taiwan warrants at the second and third orders, implying that risk averters prefer investing in China warrants to Taiwan warrants. However, there are still some pairs of China and Taiwan warrants that do not dominate each other. For example, for the pair of minimum mean return, C14 does not dominate T13 for any order. For the comparison among the maximum Jensen ratio, there is no SD between C14 and T33 for any order.

\section{[Table 3 here]}

In order to illustrate the SD relationship better, we plot the distributions of the excess returns, F and G, for China and Taiwan warrants, and the corresponding DD statistics for the pair of 
C23 and T33, as shown in Figure 1. From Figure 1, we find that F is below G for some negative returns, while $\mathrm{G}$ is below $\mathrm{F}$ for some positive returns, implying that the excess return in the China warrant is preferred in the negative domain, while the excess return in the Taiwan warrant is preferred in the positive domain. In addition, it is clear that the first-order DD statistic (T1) is negative when the returns are negative, and becomes positive when the returns are positive. These results imply that the excess return in the China warrant is preferred in the negative return and the excess return in the Taiwan warrant is preferred in the positive return. It is also worth noting that both the second- and third-order DD statistics (T2 and T3) are negative, with some regions being significant.

\section{[Figure 1 here]}

In general, all investors with increasing utility functions prefer the negative excess return in China warrants and prefer the positive excess return in Taiwan warrants. For these reasons, there is no first-order SD between China and Taiwan warrants, and no arbitrage opportunity (see Guo et al. (2017) and the references listed therein for further information) in the markets for China and Taiwan warrants.

However, China warrants dominate Taiwan warrants at the second and third orders, implying that second- and third-order risk averters prefer to invest in China as compared with Taiwan. This implies that the markets for China and Taiwan warrants are not efficient if investors are risk averters (see Qiao et al. (2012), Clark et al. (2016), and the references cited therein, for further information).

It can be concluded that China warrants could be underpriced, so that it is more difficult for China warrant issuers to make profits. This could be one of the main reasons why the market for China warrants closed. Another reason that China presently has no warrant market is that the warrants issued by companies are used for compensation in the share reform during 2004 to 2008, which expired in 1 to 2 years. China closed its warrants market because of the gradual expiration of reform-related warrants, excessive speculation, and lack of understanding of the warrants market by its participants.

\subsection{Volume analysis}


We further examine the market activities between the China and Taiwan warrants. In order to do so, we analyse the daily trading volumes of China and Taiwan warrants that were selected in Section 3.1. In order to make the comparison practical, we convert both currencies in USD and exhibit the daily trading dollar value when the prices are in USD. These results are presented in Table 4 for China and Taiwan warrants.

\section{[Table 4 here]}

From Table 4, we find that the average daily trading volume of most China warrants is of order $10^{5}$, while that of most Taiwan warrants are of the order $10^{2}$. The average daily trading volume of individual China warrant is $10^{3}$ times greater than that of individual Taiwan warrants. Thus, it can be concluded that the China warrant market is much more active than its Taiwan counterpart.

In China, there were only 55 warrants traded in the market, but the trading volume was once ranked the highest in the world. In Taiwan, the warrant market has experienced rises and falls, but there are currently more than 10 thousand warrants issued every year. Although the total trading volumes of warrants in China and Taiwan are the highest in the world, China had far fewer warrants than did Taiwan. Thus, it is not surprising that the trading volume for “each warrant” in China is much greater than in Taiwan. Investors in China prefer warrants to stocks because of trading rules and transaction costs, as mentioned in Section 1. Thus, they are keen to trade fewer warrants available in the market, and hope to chase for the prices of warrants (Xiong and Yu, 2011). In other words, the China warrant market is predominantly speculative, which can cause a greater number of trades.

\section{Concluding Remarks}

Academics, practitioners, and policy makers are interested in examining why the warrant market in China closed. In order to study this phenomenon, Fung et al. (2009) point out the issues of over-speculation and lack of recognition of participants. Liao and Chen (2010) determine that the expiration of call warrants have a significantly negative price effect during the last few days of the sample period. Xiong and Yu (2011) find that the daily trading volume of many warrants is more than 3 times of the issuance volume. 
Chang et al. (2013) discovered that the market price of warrants is far higher than the prices from Black-Scholes models using historical volatilities. Liao et al. (2014) find that 121.64 million shares of warrants were either exercised with an immediate loss, or failed to be exercised. Powers and Xiao (2014) show that put warrant market prices averaged 1.2 yuan more than model-generated prices (over-priced), while call warrant prices averaged 1.9 yuan less (under-priced).

In this paper, we bridge a gap in the literature by using moment analysis, CAPM statistics, SD test, and volume analysis to examine investor preferences towards warrants between China and Taiwan, and investigate why the market for warrants in China closed while the market for Taiwan warrants is succeeding.

Using moment analysis, we find that the mean excess returns are, in general, higher for Taiwan warrants, while most of the mean excess returns for China warrants are negative. In addition, most of the China warrants have more significant and negative skewness, and significant and greater kurtosis than Taiwan warrants. This information implies that buying China warrants has a much higher chance for sustaining losses than Taiwan warrants. This could make investors avoid investing in China warrants which, in turn, could lead to the closure of the market for China warrants.

Using CAPM analysis, the Sharpe ratio for warrants for Taiwan is higher than for China, and the Jensen index for warrants in Taiwan is higher than in China, inferring that Taiwan warrants perform better than China warrants. In general, both the Sharpe ratio and Jensen index for warrants for Taiwan are more attractive, while those for China are too negative. This could make investors avoid investing in China warrants which, in turn, could lead to the closure of the market for China warrants. On the other hand, the Treynor index for China warrants shows that they are very volatile which, in turn, could also lead to the closure of the market of China warrants.

In summary, CAPM analysis demonstrates that Taiwan warrants perform better than China warrants in terms of the Sharpe ratio and Jensen index. In addition, the China warrant market is volatile for investors, according to the Treynor ratio. Therefore, China closed its warrant market after the end of the share-split reform, whereby the warrants expired completely in 2010. In the future, China might think about reopening its warrant market and learning from 
mature-covered warrant markets, such as Taiwan, how to inhibit excess speculation and to educate warrant investors.

Using SD analysis, there are no arbitrage opportunities between the China and Taiwan warrant markets, but the warrant markets in China and Taiwan are not efficient because the China warrant market dominates Taiwan at the second and third orders, implying that secondorder and third-order risk averters prefer to invest in China compared with Taiwan. This implies that the warrant issuers prefer to issue Taiwan warrants than China warrants, which could be another reason why the warrant market in China closed.

Based on volume analysis, the empirical findings show that the average daily trading volume of individual China warrants is $10^{3}$ times higher than individual Taiwan warrants, so that the China warrant market is much more active than its counterpart in Taiwan. This would seem to suggest that there are more speculative activities in the China warrant market than the Taiwan warrant market which, in turn, could lead to China’s decision to close its warrant market.

Another reason for China presently having no warrant market is that warrants issued by companies are used for compensation in the share reform during the period 2004 to 2008, which expired in 1-2 years. China closed the warrant market because of the gradual expiration of reform-related warrants, excessive speculation, and lack of understanding of the warrants market by its participants.

The findings in the paper are important for investors for their investment decisions regarding Taiwan and China warrants, challenging for academics in modelling Taiwan and China warrants, and useful for policy makers for their policy making related to Taiwan warrants and China warrants. In the future, China might rethink reopening its warrant market and learning from mature-covered warrant markets such as Taiwan how to inhibit excess speculation and to educate warrant investors.

The paper investigated the preferences of risk averters to invest in warrants between China and Taiwan. Extensions include using other tools to compare the preferences for risk averters to invest in warrants between China and Taiwan, as well as investigate the preferences of other types of investors (see Chang et al. (2016a,b,c, 2018a,b) for further information). 
Table 1

\section{Summary statistics and CAPM using daily excess returns for selected China and Taiwan warrants}

\begin{tabular}{|c|c|c|c|c|c|c|c|c|c|}
\hline $\begin{array}{c}\text { Warrant } \\
\text { code }\end{array}$ & Mean & $\begin{array}{c}\text { std. } \\
\text { dev. }\end{array}$ & skewness & kurtosis & JB & Sharpe & beta & Treynor & Jensen \\
\hline C06 & -0.0201 & 0.0781 & -3.7196 & 33.9411 & 10084.75 & -0.2579 & 0.0150 & -1.3384 & -0.0186 \\
\hline C12 & -0.0186 & 0.1440 & -13.0898 & 242.2479 & 1160912.00 & -0.1294 & -0.0009 & 20.5741 & -0.0183 \\
\hline C14 & -0.0638 & 0.2956 & -8.3235 & 80.9023 & 30407.42 & -0.2157 & -0.0059 & 10.8959 & -0.0624 \\
\hline C23 & 0.0011 & 0.0555 & 0.4351 & 5.1238 & 52.02 & 0.0204 & 0.0175 & 0.0647 & -0.0056 \\
\hline C44 & -0.0057 & 0.0300 & 2.7879 & 24.6026 & 6885.69 & -0.1527 & 0.0115 & -0.4943 & -0.0058 \\
\hline C47 & -0.0365 & 0.3155 & -13.5417 & 197.7772 & 377048.90 & -0.1158 & -0.0174 & 2.0965 & -0.0298 \\
\hline C52 & -0.0270 & 0.2297 & -13.2963 & 195.6075 & 373322.80 & -0.1175 & 0.0397 & -0.6796 & -0.0405 \\
\hline C55 & -0.0189 & 0.1171 & -2.2507 & 29.5247 & 7117.58 & -0.1615 & 0.0003 & -60.9548 & -0.0190 \\
\hline T1 & -0.0511 & 0.2409 & -0.4242 & 12.6574 & 454.26 & -0.2121 & 0.0814 & -0.6280 & -0.0565 \\
\hline T12 & -0.0341 & 0.4486 & -0.0494 & 20.9576 & 1679.60 & -0.0760 & 0.0289 & -1.1812 & -0.0307 \\
\hline T13 & -0.0573 & 0.2730 & 1.3731 & 15.5192 & 800.82 & -0.2100 & 0.0232 & -2.4702 & -0.0560 \\
\hline T15 & -0.0374 & 0.1388 & -2.2828 & 22.0487 & 2925.68 & -0.2693 & 0.0225 & -1.6632 & -0.0343 \\
\hline T17 & 0.0053 & 0.0588 & 1.9440 & 11.7270 & 475.41 & 0.0892 & 0.0056 & 0.9310 & 0.0037 \\
\hline T25 & -0.0434 & 0.1742 & 0.2863 & 11.0227 & 336.94 & -0.2491 & 0.0103 & -4.2091 & -0.0441 \\
\hline T26 & -0.0032 & 0.2247 & 0.9245 & 5.1186 & 41.19 & -0.0144 & 0.1324 & -0.0245 & -0.0109 \\
\hline T33 & 0.0128 & 0.1545 & -1.0409 & 10.6930 & 320.22 & 0.0829 & 0.0523 & 0.2451 & 0.0094 \\
\hline
\end{tabular}

\section{Notes:}

C06 - min Sharpe

C12 - max Treynor

C14 - min mean, min Jensen

C23 - max mean, max Sharpe \& max Jensen

C44-min s.d.

C47 - max s.d., min beta

C52 - max beta

C55 - min Treynor

$\mathrm{T} 1$ - min Jensen

T12 - max s.d.

T13 - min mean

T15 - min Sharpe

T17 - min s.d., max Sharpe, min beta, max Treynor

T25 - min Treynor

T26 - max beta

T33 - max mean, max Jensen 


\section{Table 2}

\section{Results for selected pairwise comparison}

\begin{tabular}{|c|c|c|c|}
\hline Pairwise Comparison & T test & F test & MV dominance \\
\hline C14-T13 & $\begin{array}{c}\mu_{C}<\mu_{T} \\
-0.1474\end{array}$ & $\begin{array}{l}\sigma_{\mathrm{C}}>\sigma_{\mathrm{T}} \\
1.1529\end{array}$ & No \\
\hline C23-T33 & $\begin{array}{l}\mu_{C}<\mu_{T} \\
-1.041\end{array}$ & $\begin{array}{c}\sigma_{\mathrm{C}}<\sigma_{\mathrm{T}} \\
7.7611^{* * *}\end{array}$ & $\mathrm{C} 23>_{M V} \mathrm{~T} 33$ \\
\hline C44-T17 & $\begin{array}{c}\mu_{\mathrm{C}}<\mu_{\mathrm{T}} \\
-2.6106^{* * *}\end{array}$ & $\begin{array}{c}\sigma_{\mathrm{C}}<\sigma_{\mathrm{T}} \\
3.8564^{* * *}\end{array}$ & No \\
\hline C47-T12 & $\begin{array}{c}\mu_{C}<\mu_{T} \\
-0.0597\end{array}$ & $\begin{array}{c}\sigma_{\mathrm{C}}<\sigma_{\mathrm{T}} \\
2.0222 * * *\end{array}$ & $\mathrm{C} 47>_{M V} \mathrm{~T} 12$ \\
\hline C06-T15 & $\begin{array}{l}\mu_{\mathrm{C}}>\mu_{\mathrm{T}} \\
1.6191\end{array}$ & $\begin{array}{c}\sigma_{\mathrm{C}}<\sigma_{\mathrm{T}} \\
3.1598 * * *\end{array}$ & $\mathrm{C06}>_{M V} \mathrm{~T} 15$ \\
\hline C23-T17 & $\begin{array}{c}\mu_{\mathrm{C}}<\mu_{\mathrm{T}} \\
-0.6578\end{array}$ & $\begin{array}{l}\sigma_{\mathrm{C}}<\sigma_{\mathrm{T}} \\
1.1249 \\
\end{array}$ & No \\
\hline C47-T17 & $\begin{array}{c}\mu_{\mathrm{C}}<\mu_{\mathrm{T}} \\
-1.4663\end{array}$ & $\begin{array}{c}\sigma_{\mathrm{C}}>\sigma_{\mathrm{T}} \\
28.7523 * * *\end{array}$ & $\mathrm{C} 47>_{M V} \mathrm{~T} 17$ \\
\hline C52-T26 & $\begin{array}{c}\mu_{\mathrm{C}}<\mu_{\mathrm{T}} \\
-0.9425\end{array}$ & $\begin{array}{l}\sigma_{\mathrm{C}}>\sigma_{\mathrm{T}} \\
1.0449\end{array}$ & No \\
\hline C55-T25 & $\begin{array}{l}\mu_{C}<\mu_{T} \\
1.5869\end{array}$ & $\begin{array}{c}\sigma_{\mathrm{C}}<\sigma_{\mathrm{T}} \\
2.2131^{* * *}\end{array}$ & $\mathrm{C} 55>_{M V} \mathrm{~T} 25$ \\
\hline C12-T17 & $\begin{array}{c}\mu_{\mathrm{C}}<\mu_{\mathrm{T}} \\
-1.8125^{*}\end{array}$ & $\begin{array}{c}\sigma_{\mathrm{C}}>\sigma_{\mathrm{T}} \\
5.9872 * * *\end{array}$ & $\mathrm{~T} 17>_{M V} \mathrm{C} 12$ \\
\hline C23-T01 & $\begin{array}{c}\mu_{\mathrm{C}}>\mu_{\mathrm{T}} \\
3.1743^{* * * *}\end{array}$ & $\begin{array}{c}\sigma_{\mathrm{C}}<\sigma_{\mathrm{T}} \\
18.8615^{* * *}\end{array}$ & $\mathrm{C} 23>_{M V} \mathrm{T01}$ \\
\hline C14-T33 & $\begin{array}{c}\mu_{\mathrm{C}}<\mu_{\mathrm{T}} \\
-2.4578^{* *}\end{array}$ & $\begin{array}{c}\sigma_{\mathrm{C}}>\sigma_{\mathrm{T}} \\
3.5309 * * *\end{array}$ & $\mathrm{~T} 33>_{M V} \mathrm{C} 14$ \\
\hline
\end{tabular}

\section{Notes:}

C14-T13 is the pair of mean min, C23-T33 is the pair of mean max.

C44-T17 is the pair of s.d min, C47-T12 is the pair of s.d max.

C06-T15 is the pair of Sharpe ratio min, C23-T17 is the pair of Sharpe ratio max.

C47-T17 is the pair of beta min, C52-T26 is the pair of beta max.

C55-T25 is the pair of Treynor ratio min, C12-T17 is the pair of Treynor ratio max.

C23-T01 is the pair of Jensen ratio $\mathrm{min}, \mathrm{C} 14-\mathrm{T} 33$ is the pair of Jensen ratio max. 


\section{Table 3}

\section{SD Results for selected pairwise comparison}

\begin{tabular}{|l|l|}
\hline Pairwise Comparison & Ascending SD \\
\hline C14-T13 & No SD \\
\hline C23-T33 & $\mathrm{C}>_{2,3} \mathrm{~T}$ \\
\hline C44-T17 & $\mathrm{C}>_{2,3} \mathrm{~T}$ \\
\hline C47-T12 & $\mathrm{C}>_{2,3} \mathrm{~T}$ \\
\hline C06-T15 & $\mathrm{C}>_{2,3} \mathrm{~T}$ \\
\hline C23-T17 & $\mathrm{C}>_{2,3} \mathrm{~T}$ \\
\hline C47-T17 & \\
\hline C52-T26 & No SD \\
\hline C55-T25 & $\mathrm{C}>_{2,3} \mathrm{~T}$ \\
\hline C12-T17 & $\mathrm{C}>_{2,3} \mathrm{~T}$ \\
\hline C23-T01 & $\mathrm{C}>_{2,3} \mathrm{~T}$ \\
\hline C14-T33 & $\mathrm{C}>_{2,3} \mathrm{~T}$ \\
\hline
\end{tabular}

\section{Notes:}

C14-T13 is the pair of mean min, C23-T33 is the pair of mean max.

C44-T17 is the pair of s.d min, C47-T12 is the pair of s.d max.

C06-T15 is the pair of Sharpe ratio min, C23-T17 is the pair of Sharpe ratio max.

C47-T17 is the pair of beta min, C52-T26 is the pair of beta max.

C55-T25 is the pair of Treynor ratio min, C12-T17 is the pair of Treynor ratio max.

C23-T01 is the pair of Jensen ratio min, C14-T33 is the pair of Jensen ratio max. 


\section{Table 4}

\section{Summary statistics of trading volume (in USD) for selected China and Taiwan warrants}

\begin{tabular}{|c|c|c|c|c|c|}
\hline Warrant code & Mean & std. dev. & skewness & kurtosis & JB \\
\hline C06 & 96150.9500 & 73283.1200 & 2.1843 & 10.0706 & 690.7704 \\
\hline C12 & 173603.0000 & 324388.6000 & 3.4949 & 17.0166 & 4926.9010 \\
\hline C14 & 46306.6400 & 44987.5000 & 1.8837 & 7.1179 & 150.5576 \\
\hline C23 & 55458.4900 & 46573.7300 & 1.9508 & 8.4068 & 440.8489 \\
\hline C44 & 214101.4000 & 178940.0000 & 1.9563 & 7.5217 & 718.0678 \\
\hline C47 & 40012.9900 & 40078.6000 & 2.3406 & 10.4683 & 760.7066 \\
\hline C52 & 59475.6700 & 51874.5500 & 2.4878 & 10.7968 & 848.3305 \\
\hline C55 & 48996.5800 & 60061.5300 & 3.2302 & 16.5166 & 2216.2940 \\
\hline T1 & 15.3537 & 103.6143 & 10.5616 & 113.3553 & 61544.3700 \\
\hline T12 & 18.4588 & 72.0669 & 9.8558 & 105.4079 & 57098.5700 \\
\hline T13 & 25.7770 & 127.7570 & 10.4158 & 111.5797 & 60098.8800 \\
\hline T15 & 11.4235 & 75.4091 & 13.2409 & 178.1744 & 240636.5000 \\
\hline T17 & 0.1405 & 0.4666 & 4.8718 & 29.5315 & 4194.0060 \\
\hline T25 & 37.7894 & 74.4648 & 2.3908 & 8.2631 & 265.4654 \\
\hline T26 & 79.8744 & 149.2158 & 7.2949 & 69.3507 & 24230.2100 \\
\hline T33 & 107.3186 & 117.9072 & 2.8163 & 14.5546 & 839.9515 \\
\hline
\end{tabular}


Figure 1

Ascending DD Statistics Distribution for C23-T33

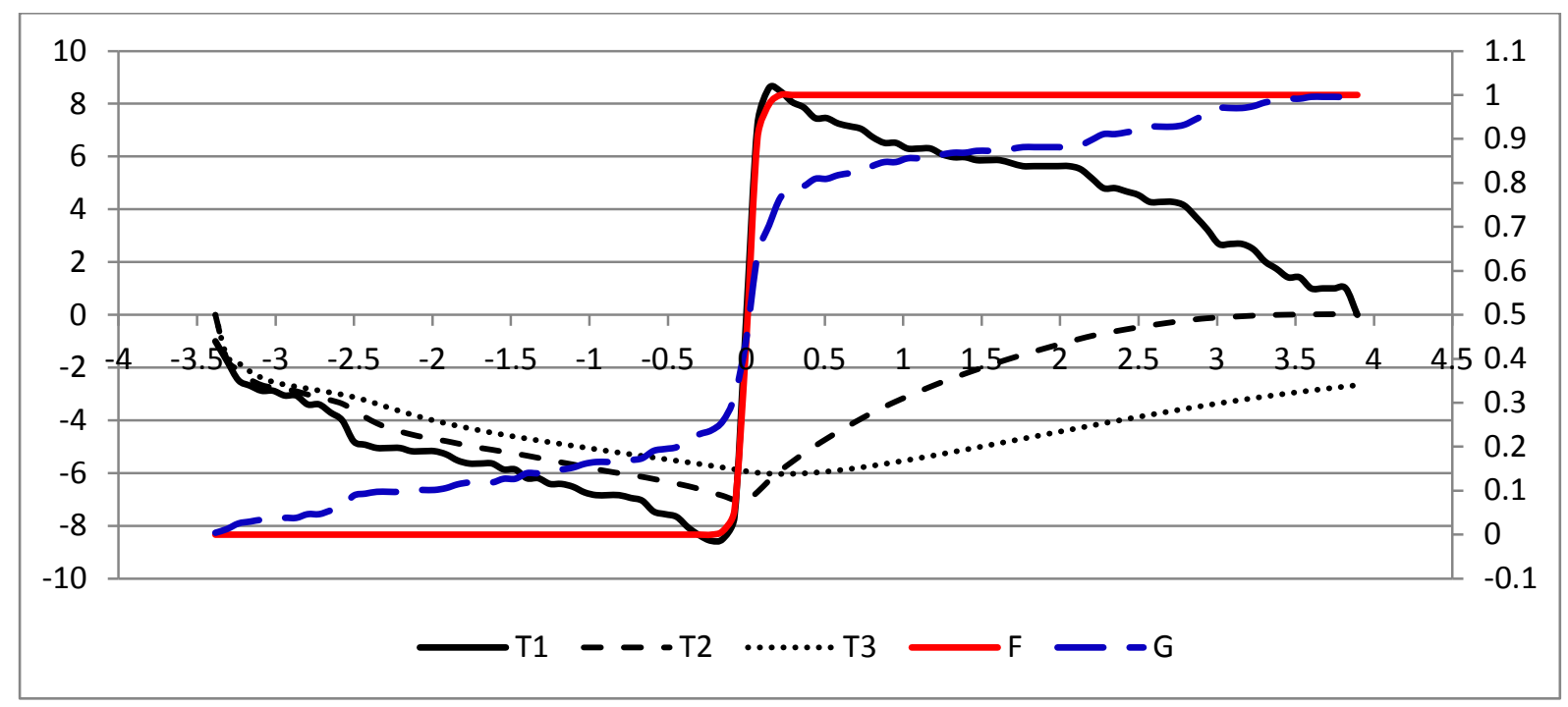

Note: $T_{j}$ is the test statistic defined in (3) for $j=1,2$, and 3. $F$ and $G$ are the CDFs of the excess warrant returns for C23 and T33, respectively. 


\section{References}

Abid, F., Mroua, M., Wong, W.K. (2019). The Impact of Option Strategies in Financial Portfolios Performance: Mean-Variance and Stochastic Dominance Approaches, Finance India, 23(2), 503-526.

Abid, F., Leung, P.L., Mroua, M., Wong, W.K. (2014). International Diversification versus Domestic diversification: Mean-Variance Portfolio Optimization and stochastic dominance approaches, Journal of Risk and Financial Management, 7(2), 45-66.

Aitken, M., Segara, R. (2005). Impact of warrant introductions on the behaviour of underlying stocks: Australian evidence. Accounting \& Finance, 45, 127-144.

Alghalith, M., Guo, X., Wong, W.K., Zhu, L.X. (2016). A General Optimal Investment Model in the Presence of Background Risk, Annals of Financial Economics, 11(1), 1650001.

Bai, Z.D., Li, H., McAleer, M., Wong, W.K. (2015). Stochastic dominance statistics for risk averters and risk seekers: An analysis of stock preferences for USA and China. Quantitative Finance, 1-12.

Bai, Z.D., Li, H., Liu, H.X., Wong, W.K. (2012). Test Statistics for Prospect and Markowitz Stochastic Dominances with Applications. Econometrics Journal, 14(2), 278-303.

Bai, Z.D., Liu, H.X., Wong, W.K. (2009). Enhancement of the applicability of Markowitz's portfolio optimization by utilizing random matrix theory. Mathematical Finance, 19, 639667.

Bartram, S.M., Fehle, F. (2007). Competition without fungibility: Evidence from alternative market structures for derivatives. Journal of Banking \& Finance, 31, 659-677.

Broll, U., Guo, X., Welzel, P., Wong, W.K., 2015, The banking firm and risk taking in a twomoment decision model, Economic Modelling, 50, 275-280.

Broll, U., Jack E. Wahl, J.E., Wong, W.K., (2006), Elasticity of Risk Aversion and International Trade, Economics Letters, 92(1), 126-130.

Chan, C.Y., de Peretti, C., Qiao, Z., Wong, W.K. (2012). Empirical test of the efficiency of UK covered warrants market: stochastic dominance and likelihood ratio test approach. Journal of Empirical Finance, 19(1), 162-174.

Chan, H.W.-H., Pinder, S.M. (2000). The value of liquidity: Evidence from the derivatives market. Pacific-Basin Finance Journal, 8, 483-503. 
Chan, R.H., Clark, E., Wong, W.K. (2016). On the Third Order Stochastic Dominance for Risk-Averse and Risk-Seeking Investors with Analysis of their Traditional and Internet Stocks, MPRA Paper No. 75002. University Library of Munich, Germany.

Chan, R.H., Chow, S.C., Guo, X., Wong, W.K. (2017). Central Moments, Stochastic Dominance, and The Moment Rules, Social Science Research Network Working Paper Series 3034903.

Chang, C.L., McAleer, M., Wong, W.K. (2016a). Behavioural, Financial, and Health \& Medical Economics: A Connection, Journal of Health \& Medical Economics, 2(1), 1-4.

Chang, C.L., McAleer, M., Wong, W.K. (2016b). Informatics, Data Mining, Econometrics and Financial Economics: A Connection, Journal of Informatics and Data Mining, 1(1), $1-5$.

Chang, C.L., McAleer, M., Wong, W.K. (2016c). Management Science, Economics and Finance: A Connection, International Journal of Economics and Management Sciences, 5(4), 1-19.

Chang, C.L., McAleer, M., Wong, W.K. (2018a). Management Information, Decision Sciences, and Financial Economics: A Connection, Journal of Management Information and Decision Sciences, forthcoming.

Chang, C.L., McAleer, M., Wong, W.K. (2018b). Big Data, Computational Science, Economics, Finance, Marketing, Management, and Psychology: Connections. Journal of Risk and Financial Management, forthcoming.

Chang, E.C., Luo, X., Shi, L., Zhang, J.E. (2013). Is warrant really a derivative? Evidence from the China warrant market. Journal of Financial Markets, 16, 165-193.

Chiang, T.C., H.H. Lean, W.K. Wong, (2008), Do REITs Outperform Stocks and FixedIncome Assets? New Evidence from Mean-Variance and Stochastic Dominance Approaches, Journal of Risk and Financial Management, 1, 1-37.

Chung, S.-L., Liu, W.-R., Tsai, W.-C. (2014). The impact of derivatives hedging on the stock market: Evidence from Taiwan's covered warrants market. Journal of Banking \& Finance, 42, 123-133.

Clark, E., Qiao, Z., Wong, W.K. (2016). Theories of Risk: Testing Investor Behaviour on the Taiwan Stock and Stock Index Futures Markets, Economic Inquiry, 54(2), 907-924.

Davidson, R., Duclos, J.Y. (2000). Statistical inference for stochastic dominance and for the measurement of poverty and inequality. Econometrica, 68, 1435-1464. 
Draper, P., Mak, B.S.C., Tang, G.Y.N. (2001). The Derivative Warrant Market in Hong Kong: Relationships with Underlying Assets. Journal of Derivatives, 8, 72-83.

Egozcue, M., Fuentes García, L., Wong, W.K., Zitikis, R. (2011). Do Investors Like to Diversify? A Study of Markowitz Preferences, European Journal of Operational Research, 215(1), 188-193.

Egozcue, M., Wong, W.K. (2010), Gains from Diversification on Convex Combinations: A Majorization and Stochastic Dominance Approach, European Journal of Operational Research, 200(3), 893-900.

Fong, W.M., Lean, H.H., Wong, W.K., (2008), Stochastic Dominance and Behavior towards

Risk: The Market for Internet Stocks, Journal of Economic Behavior and Organization, 68(1), 194-208.

Fong, W.M., Wong, W.K., Lean, H.H., (2005), International momentum strategies: a stochastic dominance, Journal of Financial Markets, 8, 89-109.

Fung, H.-G., Zhang, G., Zhao, L., 2009. China's Equity Warrants Market: An Overview and Analysis. The Chinese Economy, 42, 86-97.

Gasbarro, D., Wong, W.K., Zumwalt, J.K. (2007). Stochastic Dominance Analysis of iShares. European Journal of Finance, 13, 89-101.

Guo, X., Jiang, X.J., Wong, W.K. (2017). Stochastic Dominance and Omega Ratio: Measures to Examine Market Efficiency, Arbitrage Opportunity, and Anomaly, Economies, 5(4), 38.

Guo, X., Post, T., Wong, W.K., Zhu, L.X. (2014). Moment Conditions for Almost Stochastic Dominance, Economics Letters, 124(2), 163-167.

Guo, X., Wagener, A., Wong, W.K., Zhu, L.X. (2017). The Two-Moment Decision Model with Additive Risks, Risk Management, 20(1), 77-94.

Guo, X., Wong, W.K. (2016). Multivariate Stochastic Dominance for Risk Averters and Risk Seekers, RAIRO - Operations Research, 50(3), 575-586.

Guo, X., Wong, W.K., Zhu, L.X. (2016). Almost Stochastic Dominance for Risk Averters and Risk Seeker, Finance Research Letters, 19, 15-21.

Guo, X., Zhu, X.H., Wong, W.K., Zhu, L.X. (2013). A Note on Almost Stochastic Dominance. Economics Letters, 121(2), 252-256.

Hoang, T.H.V., Lean, H.H., Wong, W.K. (2015). Is gold good for portfolio diversification? A stochastic dominance analysis of the Paris stock exchange, International Review of Financial Analysis, 42, 98-108. 
Hoang, T.H.V., Wong, W.K., Xiao, B., Zhu, Z.Z. (2018). The seasonality of gold prices in China: Does the risk-aversion level matter? Accounting and Finance, first revision.

Hoang, T.H.V., Wong, W.K., Zhu, Z.Z. (2015). Is gold different for risk-averse and riskseeking investors? An empirical analysis of the Shanghai Gold Exchange. Economic Modelling, 50, 200-211.

Horst, J.t., Veld, C. (2008). An Empirical Analysis of the Pricing of Bank Issued Options versus Options Exchange Options. European Financial Management, 14, 288-314.

Khamlichi, A.E., Hoang, T.H.V., Wong, W.K., Zhu, Z.Z. (2018). Does the Shari'ah Screening Impact the Gold-Stock Nexus? A Sectorial Analysis, Resources Policy, first revision.

Lean, H.H., McAleer, M., Wong, W.K. (2010). Market Efficiency of Oil Spot and Futures: A Mean-Variance and Stochastic Dominance Approach. Energy Economics, 32(5), 979986.

Lean, H.H., McAleer, M., Wong, W.K. (2015). Preferences of risk-averse and risk-seeking investors for oil spot and futures before, during and after the Global Financial Crisis, International Review of Economics and Finance, 40, 204-216.

Lean, H.H., Phoon, K.F., Wong, W.K. (2013). Stochastic Dominance Analysis of CTA Funds, Review of Quantitative Finance and Accounting, 40(1), 155-170.

Lean, H.H., Smyth, R., Wong, W.K. (2007), Revisiting Calendar Anomalies in Asian Stock Markets Using a Stochastic Dominance Approach, Journal of Multinational Financial Management, 17(2), 125-141

Lean, H.H., Wong, W.K., Zhang, X.B. (2008). The size and power of some stochastic dominance tests: A Monte Carlo study for correlated heteroskedastic distributions. Mathematics and Computer in Simulation, 79, 30-48.

Leshno, M., Levy, H. (2002). Preferred by “all” and preferred by “most” decision makers: Almost stochastic dominance. Management Science, 48(8), 1074-1085.

Leung, P.L., Ng, H.Y., Wong, W.K. (2012). An Improved Estimation to Make Markowitz's Portfolio Optimization Theory Users Friendly and Estimation Accurate with Application on the US Stock Market Investment, European Journal of Operational Research, 222(1), 85-95.

Levy, H. (2015). Stochastic dominance: Investment decision making under uncertainty, Springer, New York.

Li, G., Zhang, C. (2011). Why Are Derivative Warrants More Expensive Than Options? An Empirical Study. Journal of Financial and Quantitative Analysi,s 46, 275-297. 
Liao, L., Li, Z., Zhang, W., Zhu, N. (2012). Security Supply and Bubbles: A Natural Experiment from the China warrants Market. Hsinghua University, Working Paper.

Liao, L., Li, Z., Zhang, W., Zhu, N. (2014). Exercise to Lose Money? Irrational Exercise Behavior from the China warrants Market. Journal of Futures Markets, 34, 399-419.

Liao, X.-H., Chen, K.C. (2010). Expiration Effects of Covered Warrants in China. Chinese Econom,y 43, 54-75.

Liu, Y.-J., Zhang, Z., Zhao, L. (2014). Speculation Spillovers. Management Science, 61(3), 649-664.

Lozza, S.O., Wong, W.K., Fabozzi, F.J., Egozcue, M. (2018). Diversification versus Optimal: Is There Really a Diversification Puzzle? Applied Economics, forthcoming Markowitz, H.M. (1952). Portfolio selection. Journal of Finance, 7, 77-91.

Ng, P., Wong, W.K., Xiao, Z.J. (2017). Stochastic dominance via quantile regression with applications to investigate arbitrage opportunity and market efficiency. European Journal of Operational Research, 261(2), 666-678.

Niu, C.Z., Wong, W.K., Xu, Q.F. (2017), Kappa Ratios and (Higher-Order) Stochastic Dominance, Risk Management, 19(3), 245-253.

Petrella, G. (2006). Option bid-ask spread and scalping risk: Evidence from a covered warrants market. Journal of Futures Markets, 26, 843-867.

Powers, E., Xiao, G. (2014). Mispricing of China warrants. Pacific-Basin Finance Journal, 30, 62-86.

Qiao, Z., Clark, E., Wong, W.K. (2012). Investors' Preference towards Risk: Evidence from the Taiwan Stock and Stock Index Futures Markets, Accounting \& Finance, 54(1), 251274.

Qiao, Z., Wong, W.K. (2015). Which is a better investment choice in the Hong Kong residential property market: a big or small property? Applied Economics, 47(16), 16701685.

Qiao, Z., Wong, W.K., Fung, J.K.W. (2013). Stochastic Dominance Relationships between Stock and Stock Index Futures Markets: International Evidence, Economic Modelling, 33, 552-559.

Scheinkman, J.A., Xiong, W. (2003). Overconfidence and Speculative Bubbles. Journal of Political Economy, 111, 1183-1219. 
Sriboonchitta, S., Wong, W.K., Dhompongsa, S., Nguyen, H.T. (2009). Stochastic Dominance and Applications to Finance, Risk and Economics, Chapman and Hall/CRC, Taylor and Francis Group, Boca Raton, Florida, USA.

Tang, K., Wang, C. (2013). Are China warrants derivatives? Evidence from connections to their underlying stocks. Quantitative Finance, 13, 1225-1240.

Tsang, C.K., Wong, W.K., Horowitz, I. (2016). Arbitrage Opportunities, Efficiency, and the Role of Risk Preferences in the Hong Kong Property Market, Studies in Economics and Finance, 33(4), 735-754.

Vieito, J.P., Wong, W.K., Zhu, Z.Z., 2015, Could The Global Financial Crisis Improve The Performance of The G7 Stocks Markets? Applied Economics, 48(12) 1066-1080.

Wong, W.K. (2017). Stochastic Dominance and Mean-Variance Measures of Profit and Loss for Business Planning and Investment. European Journal of Operational Research, 182, 829-843.

Wong W.K., Chan R. (2008). Prospect and Markowitz Stochastic Dominance. Annals of Finance, 4(1), 105-129.

Wong, W.K., Ma, C. (2008). Preferences over Meyer's location-scale family. Economic Theory, 37(1), 119-146.

Wong, W.K., Phoon, K.F. Lean, H.H. (2008). Stochastic dominance analysis of Asian hedge funds. Pacific-Basin Finance Journal, 16(3), 204-223.

Xiong, W., Yu, J. (2011). The China warrants Bubble. American Economic Review, 101, 2723-2753.

Zhu, Z.Z., Bai, Z.D., Vieito, J.P., Wong, W.K. (2018). The Impact of the Global Financial Crisis on the Efficiency of Latin American Stock Markets, Estudios de Economía, forthcoming 